\title{
Problematic Alcohol Use in Pokhara, Nepal As Assessed By CAGE Questionnaire
}

\author{
Lamichhane $\mathbf{N}^{1}$, Thapa $\mathrm{DK}^{1}$, Timsina $\mathrm{RR}^{2}$, Shrestha $\mathrm{LV}^{3}$, Sharma $\mathbf{R}^{3}$, Subedi $\mathrm{A}^{4}$ \\ 1. Associate Professsor, Department of Psychiatry, GMC, Pokhara, Nepal 2. Lecturer, Department of \\ Psychiatry, GMC, Pokhara, Nepal 3. Consultant Psychiatrist, Western Regional Hospital Pokhara, \\ Nepal 4. lecturer, Department Of Psychiatry, MCOMS, Pokhara, Nepal
}

E-mail *Corresponding author: drnrmlam@ hotmail.com

\begin{abstract}
Introduction: Nepal is known to be a hub for alcohol lovers. There is no restriction in sales despite efforts by the government of Nepal. Homemade alcohol is another major problem in the country. Although production and sale has legal policy it is far from being regulated. There has been no survey to assess the extent of problematic alcohol use in the Pokhara Municipality. This was conducted with the Objectives of $i$ ) assessing prevalence of problematic alcohol use in the community of a different Wards in Pokhara Metropolitan city and ii) To correlate this with various socio-demographic characteristics.
\end{abstract}

Material And Method: The CAGE questionnaire was administered to all adult individuals above 20 years of age, in houses selected as convenience sampling in different wards of Pokhara Metropolitan city from Jan 2017 to Dec 2017. Nursing students in the community visit were trained and instructed to fill the preformed questionnaire as per the inclusion criteria after taking the consent. Individuals who were not currently undergoing treatment for alcohol use disorders were only included.

Results: Among 136 adults who were included in this study, the prevalence of problematic alcohol use was found to be $64.7 \%$ (CAGE $\geq 2$ ). The extent of current alcohol use (n. 124, $91.2 \%$,) and problematic alcohol use (n. 82, $66.12 \%$ ) were significantly high (P-value: 0.0001$)$.

Conclusion: The prevalence of problematic alcohol use is too high in Pokhara, a tourist destination in Western Nepal. There is an urgent need to formulate a policy for alcohol use in the community taking into account the findings of this study. The distinction of traditional sanction of alcohol users and non users did not apply to this study. Problematic alcohol use was significantly high with no treatment initiate.

Keywords: Problematic Alcohol Use, Current alcohol User, CAGE Survey

\section{INTRODUCTION}

Alcohol is a psychoactive substance with dependence-producing properties that has been widely used in many cultures for centuries. Alcohol use remains a major cause of preventable death worldwide occurring prematurely. Despite its global burden, alcohol still is widely accepted as legal. ${ }^{1}$ Problematic alcohol consumption has significant impact on society in general and in particular on health status. The alcohol practice seems to have a long history in Nepal. Pivotal evidence suggests that even in pre-historic and ancient time's alcohol was consumed. Traditional use of alcohol in the rituals, cultural and social events persist till dates.

The use of alcoholic beverages has been an integral part of many cultures for thousands of years. Some people in Nepal generally believe that alcohol is a medicine for cold, pain, tension, and tiredness; some believe that the celebration, parties and festivals are success if alcohol is served. Being a multicultural and multi-ethnic country, Nepal is 
largely seen as an ambivalent society regarding alcohol use. But with the passage of time, traditional sanctions and caste-bound restraints have disappeared. ${ }^{2}$ In literature reviews, traditional barrier for alcohol use among the alcohol non-using community "Tagadhari" is getting weaker in current Nepal. ${ }^{3}$

Globally, alcohol consumption is the seventh leading risk factor for both death and the burden of disease and injury. In short, except for tobacco, alcohol accounts for a higher burden of disease than any other drug. Alcohol use is a major cause of preventable liver disease worldwide, and alcoholic liver disease is the main alcohol-related chronic medical illness ${ }^{4}$. Disease burden is the impact of a health problem as measured by financial cost, mortality, morbidity, or other indicators. It is often quantified in terms of qualityadjusted life years (QALYs) or disability-adjusted life years (DALYs), both of which quantify the number of years lost due to disease (YLDs). One DALY can be thought of as one year of healthy life lost, and the overall disease burden can be thought of as a measure of the gap between current health status and the ideal health status (where the individual lives to old age free from disease and disability). ${ }^{2,4,5}$

Alcohol use has a complex association with health. Researchers have recognised alcohol use as a leading risk factor for disease burden, and studies link its consumption to 60 acute and chronic diseases ${ }^{5}$. According to news release in 21 September 2018 more than 3 million people died as a result of harmful use of alcohol in 2016. This represents 1 in 20 deaths. More than three quarters of these deaths were among men. Overall, the harmful use of alcohol causes more than $5 \%$ of the global disease burden ${ }^{6}$.

Alcohol use is part of many cultural, religious and social practices, and provides perceived pleasure to many users. Countless scientific studies have espoused the idea that a glass of red wine a day can be good for the heart, but a new, sweeping global study published in The Lancet rejects the notion that any drinking can be healthy. No amount of alcohol is safe, according to The Global Burden of Diseases study, which analyzed levels of alcohol use and its health effects in 195 countries from 1990 to 2016. ${ }^{6}$ The report states "Our results show that the safest level of drinking is none". This level is in conflict with most health guidelines, which espouse health benefits associated with consuming up to two drinks per day." The study looked at a broad range of risks posed by alcohol consumption, including diseases, driving accidents and self-harm. According to the report, alcohol led to 2.8 million deaths in 2016. It was the leading risk factor for disease worldwide accounting for almost 10 percent of deaths among those ages 15 to $49^{7}$.

Even though $10 \%$ to $36 \%$ of patients seen by primary care physicians suffer from alcohol abuse or dependence, these disorders often remain unrecognized by primary care providers. $^{8}$ Screening for problem drinking using validated questionnaires is therefore recommended. ${ }^{9}$

This study has tried to show the other side of alcohol use disorder; the treatment gap among current alcohol users with "problematic alcohol use" as per the CAGE scores criteria.

\section{MATERIAL AND METHOD}

A cross sectional descriptive study was conducted on a total of 136 adults from different wards of, Pokhara Metropolitan city of Kaski district from Jan 2017- Jan 2018 i.e. 1 year period of the study. Respondents were permanent resident of the Pokhara Municipality. Ethical approval was taken from IRC of Gandaki Medical College. Written consent was taken from each respondent and confidentiality of information of the respondents was maintained. The information they provided were used only for research purpose. Respondents who were willing to participate and present during the study period were included in the study. Only one respondent was taken from each household. The CAGE questionnaire was administered with additional socio-demographic information as preformed by the department of psychiatry, Gandaki Medical College, Pokhara. This was a door to door survey on the basis of convenience sampling in the community. Convenience sampling is a type of non probability sampling in which people are sampled simply because they are "convenient" sources of data for researchers ${ }^{10}$.

The study respondents were the adult population (>20 years), and the outcome variable of interest was self-reported current alcohol use who were not undergoing any treatment for alcohol use disorders. "Current alcohol use" was defined as consumption of alcohol in the past 30 days $^{11}$. Independent variables were sex; age categorized as 20-30, 31-40, 41-50, 51-60, 61 and above years; religion, literacy; family type, marital status; occupation; monthly income and position in the family. "Working Age Group" was taken as those in "age groups 20-60". As per Nepal social hierarchy 
the following distinctions of "Matwali" are alcohol drinkers and "Tagadhari" the wearers of sacred threads are so called "alcohol nondrinkers" classifications were used ${ }^{12}$. The tool CAGE is used which is derived from the four questions of the tool: Cut down, Annoyed, Guilty, and Eye-opener. Item responses on the CAGE are scored 0 or 1, with a higher score as an indication of alcohol problems. A total score of 2 or greater is considered clinically significant and characterized in this study as "problematic alcohol use".

\section{CAGE Questions}

1. Have you ever felt you should cut down on your drinking?

2. Have people annoyed you by criticizing your drinking?

3. Have you ever felt bad or guilty about your drinking?

4. Have you ever had a drink first thing in the morning to steady your nerves or to get rid of a hangover (eye-opener)? ${ }^{13}$

\section{RESULT}

Overall 136 household were included. One adult member in the house above 20 years of age was included in the study. Among 136 adults who were included in this study, only $8.8 \%$ (n: 12) denied current alcohol use, $91.2 \%$ (n: 124) were current alcohol users.(Table 1) The mean age of the study sample was 47.38 years with SD of 14.3 while the mean age of current alcohol users were 48.45 (SD: 14.32) years. Age of the sample varied from minimum of 22 to maximum of 83 years.

Table 1: Current Alcohol Users among Total Sample (n=136)

\begin{tabular}{|l|l|l|l|}
\hline $\begin{array}{l}\text { Current Alcohol } \\
\text { Use }\end{array}$ & Frequency & Percent & $\begin{array}{l}\text { P- } \\
\text { value }\end{array}$ \\
\hline Yes & 124 & $91.2 \%$ & \multirow{2}{*}{0.0001} \\
\hline No & 12 & $8.8 \%$ & \\
\hline Total & 136 & 100 & \\
\hline
\end{tabular}

Further analyses were done on 124 current alcohol users to find out current problematic alcohol use and treatment gap in the community.
Eight of the respondents (5.9\%) were female and $100 \%$ of them were current alcohol users with CAGE score $\geq 2$ i.e. suggestive of problematic alcohol use.

Table 2 : Gender And Age Distribution Of Subjects

\begin{tabular}{|c|c|c|c|}
\hline Category & Frequency & Percent & P-Value \\
\hline \multicolumn{4}{|l|}{ Gender } \\
\hline Male & 116 & 94.1 & \multirow[t]{2}{*}{0.0001} \\
\hline Female & 8 & 5.9 & \\
\hline Total & 124 & 100 & \\
\hline \multicolumn{4}{|c|}{ Age in Years } \\
\hline $20-30$ & 9 & 7.3 & \multirow[t]{5}{*}{0.0001} \\
\hline $31-40$ & 42 & 33.9 & \\
\hline $41-50$ & 26 & 21.0 & \\
\hline $51-60$ & 19 & 15.3 & \\
\hline $61+$ & 28 & 22.6 & \\
\hline Total & 124 & 100 & \\
\hline
\end{tabular}

Problematic Alcohol use (CAGE $\geq 2$ ) was significantly higher in age range 31-40 years with mean $2.14 \pm 1.45$. Amongst 82 subjects out of 124 who had CAGE score $\geq 2$, sixty one $(74.39 \%)$ subjects were in the productive age group (20-60 years) while there were 96 current alcohol users in this group and only 28 (26.2\%) in 61 and above years. When Fisher's exact test were applied. The association between Cage score $\geq 2$ versus $<2$ in productive age group and current alcohol users amongst productive age group versus those above 61 years of age are considered to be extremely statistically significant. The two-tailed $\mathrm{P}$ value is less than 0.0001. (Table 2)

Among current alcohol users $44.4 \%$ were Buddhist and 55.6\% were Hindu. Regarding cast distribution 29 belonged to so-called "Tagadhari" non consumers group (Brahmin 20, Chhetri 9) and 16 (55. 17\%) of them had problematic alcohol use (CAGE score $\geq 2$ ). Among current alcohol users 56.5\% were literate, ninety (72.6\%) were living in nuclear family, one hundred sixteen $(93.5 \%)$ were married, ninety two $(74.2 \%)$ were job holders with $91(73.4 \%)$ having earnings of more than 20 thousands per month and $91(73.4 \%)$ of them were the head of the family. The association between rows (head of the family versus other members) is considered to be extremely 
statistically significant. The two-tailed $\mathrm{P}$ value is less than 0.0001. (Table 3)

Table 3: Other Socio-Demographic Distribution of Subjects ( $\mathrm{n}=124)$

\begin{tabular}{|c|c|c|c|}
\hline Category & Frequency & Percent & P-Value \\
\hline \multicolumn{4}{|l|}{ Literacy } \\
\hline Illiterate & 54 & 43.5 & \multirow[t]{2}{*}{0.05} \\
\hline Literate & 70 & 56.5 & \\
\hline \multicolumn{4}{|l|}{ Family Type } \\
\hline Nuclear & 90 & 72.6 & \multirow[t]{2}{*}{$S$} \\
\hline Joint & 34 & 27.4 & \\
\hline \multicolumn{4}{|l|}{$\begin{array}{l}\text { Marital } \\
\text { Status }\end{array}$} \\
\hline Married & 116 & 93.5 & \multirow[t]{2}{*}{$S$} \\
\hline Unmarried & 8 & 6.5 & \\
\hline \multicolumn{4}{|l|}{ Occupation } \\
\hline Job Holders & 92 & 74.2 & \multirow[t]{2}{*}{$S$} \\
\hline Others & 32 & 25.8 & \\
\hline \multicolumn{4}{|l|}{ Income } \\
\hline $10-20,000$ & 33 & 26.6 & \multirow[t]{2}{*}{$S$} \\
\hline$>20,000$ & 91 & 73.4 & \\
\hline \multicolumn{4}{|l|}{$\begin{array}{l}\text { Position In } \\
\text { Family }\end{array}$} \\
\hline Head & 91 & 73.4 & \multirow[t]{2}{*}{ S } \\
\hline Others & 33 & 26 & \\
\hline
\end{tabular}

Table 4: Showing the CAGE Score

\begin{tabular}{|l|l|l|l|}
\hline Category & Frequency & Percent & P-Value \\
\hline CAGE Score & & & \\
\hline Total Sample & & & \\
\hline$\geq 2$ & 82 & 66.1 & 0.0001 \\
\hline$<\mathbf{2}$ & 42 & 33.9 & \\
\hline Total & 124 & 100 & \\
\hline $\begin{array}{l}\text { Head Of } \\
\text { family }\end{array}$ & & & \\
\hline$\geq 2$ & 60 & 65.9 & 0.0001 \\
\hline$<\mathbf{2}$ & 31 & 34.1 & \\
\hline Total & 91 & 100 & \\
\hline
\end{tabular}

The CAGE score $\geq 2$ were found in $82(66.1 \%)$ and score $<2$ in 42 (33.9). By Fisher's exact test the two-tailed $\mathrm{P}$ value is less than 0.0001 . The association is considered to be extremely statistically significant.

\section{DISCUSSION:}

Although on 2017 February 20, the Cabinet of Nepal government has endorsed the "National Policy on Regulation and Control of Alcohol2017" that now requires each producer to put a pictorial warning that depicts liver cirrhosis and effects on other organs, covering at least 75 percent of the bottle. Also, a statutory warning that drinking is injurious to health should be prominently displayed on the bottle and restrictions in sales ${ }^{6}$. These are yet to be effectively implemented. Globally, alcohol consumption is the seventh leading risk factor for both death and the burden of disease and injury. Alcohol use accounts for $6.8 \%$ of agestandardized deaths in men and $2.2 \%$ in women, with a disproportionate effect on young people ${ }^{5}$. The overall costs associated with alcohol use represent more than $1 \%$ of the gross national product in high- and middle-income countries, with the costs of social harm (e.g., violence and road accidents) being far greater than health costs alone ${ }^{14}$. In short, except for tobacco, alcohol accounts for a higher burden of disease than any other drug ${ }^{15}$.

This study tried to identify "problematic alcohol use" in the community who had not taken any treatment related to alcohol use problem. Almost two thirds of the current alcohol users in this study were having problematic alcohol use as per the screening tool and this finding in the community is alarming. Even more than in a study in eastern Nepal where less than one thirds $(25.8 \%)$ had alcohol dependence syndrome ${ }^{16}$. Although CAGE questionnaire alone cannot reliable diagnose Alcohol Use Disorders ${ }^{16}$. When screening results are positive, the patient should be referred for further evaluation and treatment of an alcohol use problem and diagnosis. This will vary based on available resources, but ideally the patient should be sent to a psychiatrist, psychologist, or addiction treatment program centers ${ }^{17}$.

Among total survey population the statistically significant findings were of all females were having problematic alcohol use though representing small portion of the sample. Productive age groups, head of the family, breach of traditional barriers, married, nuclear family representing the problematic alcohol use groups were other statistically significant finding. Similar were findings in other studies in 
Nepal18. Involvement of head of the family, married people in productive age group in problematic alcohol use would have huge financial, social and familial impacts other than the effects to the individuals. In different studies worldwide only 1 out of 10 people get appropriate treatment ${ }^{5}$. So robust and strategic intervention in the community level is necessary.

\section{CONCLUSION:}

In many developing countries, like ours, the scale of the problem is not well understood, there is a little public awareness of the problem and legislation and enforcement are often inadequate. The findings of this study definitely point towards urgent need for treatment gap in the community, need for intervention, awareness campaigns, strict legislations and its implementation in the country. The main Limitation Of the study is that this study was based on convenience sampling the findings may be biased and may not reflect the exact scenario. It is recommended that Educational material regarding alcohol use can be given through distribution of educational leaflets, use of radio and television in developing country like ours. Formulation of strategies for stopping initiation and quitting alcohol use can be strengthened more from this study.

\section{ACKNOWLEDGEMENT:}

We take this opportunity to express sincere gratitude to the nursing students of Charak Academy, Pokhara.

\section{CONFLICT OF INTEREST: None}

\section{REFERENCES:}

1. Maharjan PL, Magar KT (2017) Prevalence of Alcohol Consumption and Factors Associated with the Alcohol Use among the Youth of Suryabinayak Municipality, Bhaktapur. I Pharma Care Health Sys 4: 168. doi:10.4172/2376-0419.1000168.

2. Kay D; Prüss A; Corvalán C In "Methodology for assessment of Environmental burden of disease" (PDF). ISEE session on environmental burden of disease. Buffalo o, 22 August 2000 WHO Consultation, Buffalo, 23-24 August 2000.

3. Shakya D. Alcohol ab/use in eastern Nepal: a review of studies. Health Renaissance 2013; Vol. 11 No.1; 74-82.)
4. Fuster D; Samet JH. (2018-09-27). "Alcohol Use in Patients with Chronic Liver Disease". New England Journal of Medicine. 379 (13): 1251-1261. doi: $10.1056 \quad /$ nejmra1715733. ISSN 00284793. PMID 30257164

5. GBD 2016 Alcohol Collaborators. Alcohol use and burden for 195 countries and territories, 19902016: a systematic analysis for the Global Burden of Disease Study 2016. Lancet 2018 August 23.

6. Kathmandu Post, in Alcohol Norm, Alcohol's Harm To Others, Democracy, Policy, Sustainable Development URL: https://www.who.int/newsroom/detail/21-09-2018-harmful-use-of-alcoholkills-more-than-3-million-people-each-year--mostof-them-men.

7. Raphelson S. No Amount Of Alcohol Is Good For Your Health, Global Study Says. August 24, 2018. Cited https://www.npr.org/2018/08/24/641618937/noamount-of-alcohol-is-good-for-your-health-globalstudy-claims.

8. Buchsbaum DG, Buchanan RG, Centor RM, Schnoll SH, Lawton MJ. Screening for alcohol abuse using CAGE scores and likelihood ratios. Ann Intern Med. 1991;115:774-7

9. Bradley KA, Bush KR, McDonell MB, Malone T, Fihn SD. Screening for problem drinking: comparison of CAGE and AUDIT. Ambulatory Care Quality Improvement Project (ACQUIP). Alcohol Use Disorders Identification Test. J Gen Intern Med. 1998;13(6):379-388. doi:10.1046/j.1525-1497.1998.00118

10. Lavrakas, P. J. (2008).Encyclopedia of survey research methods Thousand Oaks, CA: Sage Publications, Inc. doi: 10.4135/9781412963947

11. Substance Use Screening \& Assessment Instruments Database. Alcohol And Drug Abuse Institute University of Washington. URL: http://lib.adai.washington.edu/instruments.

12. Bennett, Lynn, Dahal Dilli Ram and Govindasamy Pav, 2008. Caste, Ethnic and Regional Identity in Nepal: Further Analysis of the 2006 Nepal Demographic and Health Survey. Calverton, Maryland, USA: Macro International Inc.

13. Prüss-Üstün, A; Mathers, C.; Corvalán, Carlos; Woodward, A. (2003). Assessing the environmental burden of disease at national and local levels: Introduction and methods. WHO Environmental Burden of Disease Series. 1. Geneva: World Health Organization. ISBN 978-9241546201.

14. Rehm J, Mathers C, Popova S, Thavorncharoensap M, Teerawattananon Y, Patra J. Global burden of disease and injury and economic cost attributable to alcohol use and alcohol-use disorders. Lancet 2009; 373:2223-33.

15. GBD 2016 Causes of Death Collaborators. Global, regional, and national agesex specific mortality for 264 causes of death, 1980-2016: a systematic 
analysis for the Global Burden of Disease Study 2016. Lancet 2017;390:1151-210.

16. Ewing JA. Detecting Alcoholism The CAGE Questionnaire. JAMA. 1984;252(14):1905-1907.

17. Jhingan $H^{1}$, Shyangwa $P$, Sharma A et al. Prevalence of alcohol dependence in a town in Nepal as assessed by the CAGE questionnaire. Addiction. 2003 Mar;98(3):339-43.

18. Treatment for Alcohol Problems: Finding and Getting Help. NIH Publication No. 14-7974 Published $2014 . \quad$ URL: https://www.niaaa.nih.gov/publications/ treatment.pdf. 